\title{
Inhalt des zweiten Bandes
}

Zum zweiten Band der Edition . . . . . . . . . V V Verzeichnis der abgekürqt zitierten Literatur . . . . . . XIX

10. 〈Deutsche Predigten〉 $1508 \ldots \ldots$. . . . 1

I. 〈Der Berg der Betrachtung 〉 . . . . . . 7

II. 〈18 Eigenschaften eines guten Christenpilgers $\rangle \ldots \ldots \ldots \ldots \ldots \ldots$

III. 〈7 geistliche Märkte $\rangle \ldots \ldots \ldots 161$

IV a. 〈7 Zeichen des sterbenden Menschen $\ldots . .176$

$I V b$. 〈Wie der Mensch zwischen Natur und Gnade erkennen kann $\quad \ldots \ldots \ldots . \ldots . \ldots 186$

$I V c .\langle 19$ Zeichen eines harten Herzens $\rangle .. . . .196$

$I V d$. 〈Vom Verhärten und Erweichen des Menschenherzens $\rangle \ldots \ldots \ldots . \ldots . \ldots 208$

V. 〈9 Früchte eines rechten Klosterlebens〉 . . 223

$V I .\langle 7$ Eselhalfter $\rangle \ldots \ldots \ldots \ldots . \ldots . \ldots 315$

$V I I .\langle 3$ Vorbilder der Nächstenliebe $\rangle \ldots . . . .394$

VIII. 〈Übungen der Tugend $\rangle$. . . . . . . . . . . 444

$I X$. 〈Warum Johannes Chrysostomus Goldmund heißt $\rangle \ldots \ldots \ldots \ldots . \ldots \ldots 46 . \ldots \ldots$

$X$. 〈Wie der Mensch sich selbst erkennt〉. . . 478

$X I$. 〈Erklärung des Bildes vom Baum des $\mathrm{Za}$ cheus $\rangle \ldots \ldots \ldots . \ldots . \ldots 496$

XII. 〈7 Qualen der geistlichen Hölle auf Erden〉 498

$X I I I .\langle 5$ Akte des Heils am Menschen $\ldots . . . .510$

$X I V .\langle$ Brief an die Reuerinnen zu Straßburg. .516

$X V .\langle$ Der Baum des Zacheus $\rangle \ldots \ldots . . . . . . . .518$

XVI. 〈Register $\ldots \ldots \ldots \ldots \ldots \ldots 46$

Scblußkolopbon ............... 571 
808

Variantenverzeichnis . . . . . . . . . . . 573

Nacbwort des Herausgebers . . . . . . . . . . . . 729

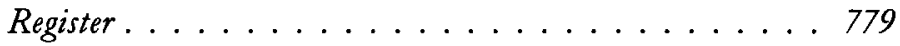

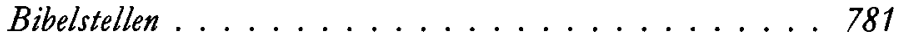

Autoren und Werke . . . . . . . . . . . . . 783

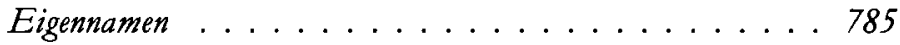

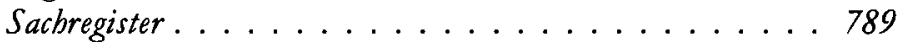

Exempla und Vergleiche ............. 805 


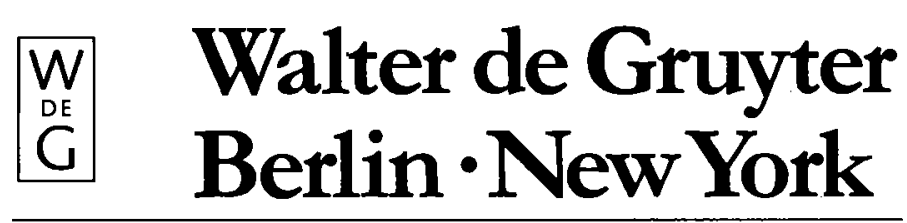

Ausgaben Deutscher Literatur des XV. bis XVIII. Jahrhunderts

A

Herausgegeben von Hans-Gert Roloff

Alle Bände sind in Leinen gebunden

123 Thomas Naogeorg, Sämtliche Werke - Band 4, Zweiter Teil: Hieremias, Iudas Iscariotes, mit zeitgenössischen Übersetzungen. Hrsg. v. Hans-Gert Roloff. IV, S. 425-872. 1987.

124 Johannes Riemer, Werke - Band 4: Vermischte Schriften. Hrsg. v. Helmut Krause. IV, 485 S. 1987.

125 Johann Christian Hallmann, Sämtliche Werke - Band 3, Erster Teil: Vermischte dramatische Stücke: Urania. Antiochus und Stratonica. Adonis und Rosibella. Hrsg. v. Gerhard Spellerberg. IV, 441 S. 1987.

126 Johann Christian Hallmann, Sämtliche Werke - Band 3, Zweiter Teil: Vermischte dramatische Stücke: Adelheide. Heraclius. Hrsg. v. Gerhard Spellerberg. IV, S. 443-721. 1987.

127 Christian Weise, Sämtliche Werke - Band 6: Biblische Dramen III. Hrsg. v. John D. Lindberg. IV, 467 S. 1988.

128 Daniel Czepko, Sämtliche Werke - Band 3: Epische und dramatische Dichtung. Hrsg. v. Hans-Gert Roloff und Marian Szyrocki. IV, 427 S. 1988.

129 Johannes Geiler von Kaysersberg, Sämtliche Werke · Erster Teil: Die Deutschen Schriften, Erste Abteilung: Die zu Geilers Lebzeiten erschienenen Schriften, Band 1. Hrsg. v. Gerhard Bauer. XLVI, 572 S. 1989. 
130 Daniel Czepko, Sämtliche Werke - Band 1, Erster Teil: Lyrik in Zyklen. Hrsg. v. Hans-Gert Roloff und Marian Szyrocki. IV, 382 S. 1989.

131 Daniel Czepko, Sämtliche Werke - Band 1, Zweiter Teil: Lyrik in Zyklen. Hrsg. v. Hans-Gert Roloff und Marian Szyrocki. IV, S. 383-833. 1989.

132 Johann Christoph Gottsched, Ausgewählte Werke - Band 5, Dritter Teil: Erste Gründe der gesammten Weltweisheit (Variantenverzeichnis). Hrsg. v. P. M. Mitchell, bearb. v. Otto Tetzlaff. IV, 299 S. 1989.

133 Philipp von Zesen, Sämtliche Werke - Band 7: Assenat. Hrsg. v. Ferdinand van Ingen. IV, 626 S. 1990.

134 Georg Wickram, Sämtliche Werke - Band 13, Erster Teil: Ovids Metamorphosen. Hrsg. v. Hans-Gert Roloff, Textredaktion Lothar Mundt. IV, 490 S. 1990.

135 Georg Wickram, Sämtliche Werke - Band 13, Zweiter Teil: Ovids Metamorphosen. Hrsg. v. Hans-Gert Roloff, Textredaktion Lothar Mundt. IV, S. 491-896. 1990.

136 Lateinische Osterfeiern und Osterspiele. Hrsg. v. Walther Lipphardt $\uparrow$. Teil VII: Kommentar (LOO 1-630). Aus dem Nachlaß hrsg. v. Hans-Gert Roloff, redaktionell bearb. v. Lothar Mundt. XXXII, 545 S. 1990.

137 Lateinische Osterfeiern und Osterspiele. Hrsg. v. Walther Lipphardt $\dagger$. Teil VIII: Kommentar (LOO 631 -832). Aus dem Nachlaß hrsg. v. Hans-Gert Roloff, redaktionell bearb. v. Lothar Mundt. VI, S. 547-847. 1990.

138 Lateinische Osterfeiern und Osterspiele. Hrsg. v. Walther Lipphardt f. Teil IX: Kommentar (Repertorium der gesungenen und gesprochenen Texte). Aus dem Nachlaß hrsg. v. Hans-Gert Roloff, redaktionell bearb. v. Lothar Mundt. VIII, S. 849-1122. 1990.

139 Johannes Geiler von Kaysersberg, Sämtliche Werke - Erster Teil: Die deutschen Schriften, Erste Abteilung: Die zu Geilers Lebzeiten erschienenen Schriften, Band 2. Hrsg. v. Gerhard Bauer. XX, 808 S. 1991. 

